\title{
The Characteristics of Aluminum Casting Product Using Centrifugal Casting Machine
}

\author{
Didik Nurhadiyanto, Mujiyono, Febrianto Amri Ristadi \\ Universitas Negeri Yogyakarta \\ Yogyakarta, Indonesia \\ didiknur@uny.ac.id
}

\begin{abstract}
Centrifugal casting for aluminum not develop yet. The aim of this research are to know the process of centrifugal casting and the characteristic of casting product. The methods used in this research is casting test for silinder aluminum. The ability of centrifugal casting tested using porous, hardness and microstructure of casting product. The result of this research was the casting process include prepare of blast furnace and centrifugal casting machines, aluminum smelting, casting, casting product release, and cleaning. The porous occurs in the inside of diameter.To obtain the required casting, it is necesssary to estimate the materials. It is very importance to predict the volume of materials.The optimum velocity of aluminum material was 1000 RPM. From the microstructure test we can concluded that the boundary in the outer diameter is closest. This is in accordance with the hardness test and the existing theory, that the outside centrifugal force increasingly and compress the material.
\end{abstract}

Keywords: aluminum, centrifugal casting, porosity, hadnes test, rotational Seed

\section{INTRODUCTION}

Centrifugal casting machine which produce cylindrical part still developed in the industry. The casting part reducing porosity and increasing density, Chirita et al. [1] and Guajun et al. [2]. This machine could be produced to cast small components.

The cancer disease is deadly disease in the world. Until now, the disease is difficult to cure. Researcher has a challenge of finding alternative steps to tackle the cancer disease. One of the research that is being done is a cancer therapy system using boron neutron capture cancer therapy (BNCT). The BNCT therapy need collimator to direct the movement of newtrons. Collimator is a long pipe from nickel material.

The method use for product of collimator is influence the mechanics strength, microstructure, and the quality of collimator. The local of collimator casting industries using gravity casting. The gravitiy casting has a weakness, ie. complex getting system which are runner design and in gate should be proportional, raiser design and gas line should exactly, and molding sand. This method caused the defect potential, ie. porosity, due to the incorrect flow, and cavity due to high depeciation. Most of small industries in Ceper, Klaten, Central Java using the sand mold gravity casting. These industries never conducted casting of pure nickel with concentration above $90 \%$, but they have been susccessfull conducted casting of cast iron untill stainless steel.
Oyewole et al. [3] designed the centrifugal casting machine. The design and fabrication of a centrifugal casting machine was successfully carried out. The mold was bolted to the base plate which could rotate at moderate speeds thereby forcing the molten metal against the inner wall of the mold. This machine could be used to cast small engineering components. Madhusudhan et al. [4] investigated the properties of centrifugal casting at different rotational speed. The molten was metal. At speed around $800 \mathrm{rpm}$ casting shows fine grains and harder metal compared to the casting at lower speed.

Based on the information above, we design centrifugal casting for collimator product. We hope the centrifugal casting method will solve the defect problem of collimator. For the initial research we used the aluminum material.

The aim of present research is to know the characteristic of aluminum casting product using centrifugal casting. This characteristic based on microstructure and hardness testing.

\section{MATERIAL AND METHOD}

The material used in present research was aluminum. The reason for using aluminum is the similar characteristic between aluminum and nickel but aluminum is cheaper than nickel. The basic difference characteristic of nickel and aluminum is nickel more rapidly solidification than aluminum.

Cantrifugal casting used for the casting process. The design of machine adopted turning machine system because having similar characteristic. Working system of centrifugal casting is aluminum fluid poured into rotating mold steel using a funnel, see Fig. 1.

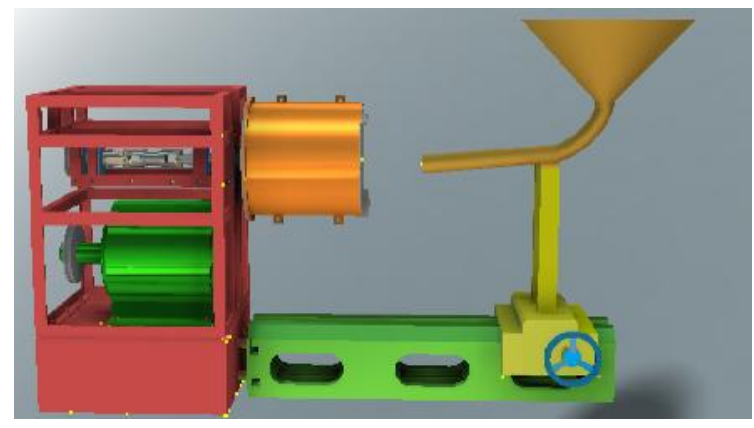

Fig. 1. The centrifugal casting 
Vibration of centrifugal casting must be minimized, because the vibration effect make the product not precision. The electric motor 5,5 HP 3 phase which connected using pulley and belt system. In centrifugal casting a permanent mold is rotating about its axis at high speeds as the molten metal poured. The paramater of centrifugal casting is speed of mold, Suryawanshi et al. [5]. The molten metal is centrifugally thrown to wards the in side mold wall where it solidifies after cooling, Rajeshwari et al. [6]. Mold and shaft connected to lathes dibble system. At the end of the mold is placed on the stand so that more stable. Setting rotational speed using an inverter that changes the speed continously.

Tachometer system used proximity and display. So, we can read the spindle speed directly. It is very easy to know the mold rotational speed.

The contruction of centrifugal casting designed that we can use horizontal and vertical casting. In this research, we used the harizontal casting.

The component of centrifugal casting i.e. chuck shows in Fig. 2, chuck assembly in Fig. 3. Chuck used to hold the mold casting. This chuck rotated through the chuck shaft connected to a motor.

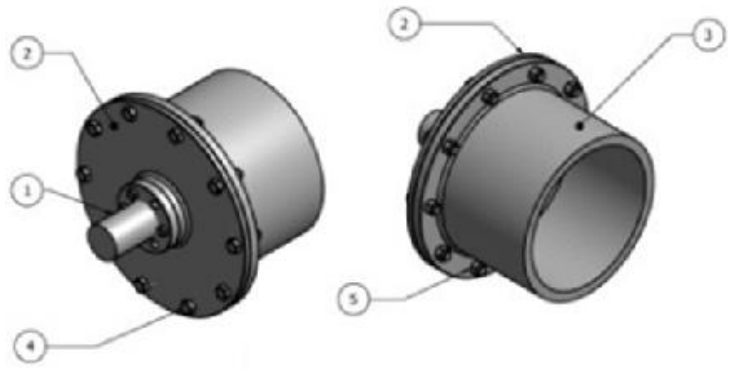

Remark:

\section{Chuck shaft}

2. Bushing

3. Mold

4. Bolt

5. Hex nut

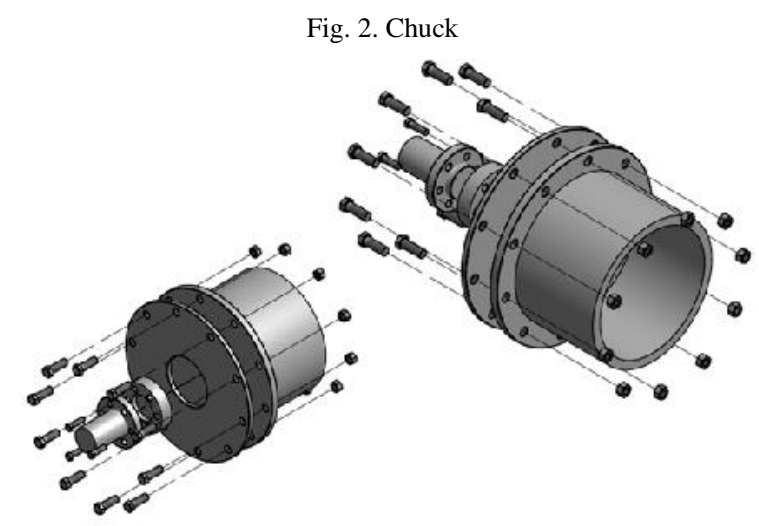

Fig. 3. Assembly chuck
Aluminum smelting process used electric arc furnace (EAF). This furnace capable for smelting until $1800^{\circ} \mathrm{C}$. The EAF is equipment used for metal melting process, in which metal heated and melted using electric arc from electrode.

There were two kinds of product test, they are microstructure analysis and hardnes testing. The data retrieval for microstructure and hardnes testing were done radially, start from outer to inner diameter. The hardness result in HRC and microstructure using Figure using 100 and 400 times magnification. The data of microstructur and hardness was take in four simetric side of the circle. We called side 1, 2, 3 and 4 . Every one side was taken 10 points from outer to inner diameter. This method to know the uniformity results.

Firstly we prepared material and tool for centrifugal casting making. Manufacture for centrufugal casting include the machine of centrifugal casting, control system, rotational speed reader, and mold holder system. After ready, next step is asembly and test the performance of centrifugal casting. The performance of machine tested using microstructure and hardness analysis. Beside that the rotational speed reader using the inverter.

Centrifugal force in certain point of aluminum material, which has radius $r$ is like equation (1) [7]. The gravitational force of aluminum mass is like equation (2). The gravitational force (GF) shows in equation (3).

$$
\begin{aligned}
& \mathrm{CF}=\frac{\mathrm{mv}^{2}}{\mathbf{r}} \\
& \mathrm{GF}=\mathrm{mg}
\end{aligned}
$$

G factor $=\frac{\mathrm{CF}}{\mathrm{GF}}=\frac{\mathrm{mv}^{2}}{\mathrm{r} \cdot \mathrm{mg}}=\frac{\mathrm{v}^{2}}{\mathrm{rg}}$

The rotational speed is 50-100 times Gfactor for metal mold. The high rortational speed caused stress excess stress and the hotters at the outer of cast result surface. The desired rotational speed was calculated using equation (4). The rotational of calculation result was $970,87 \mathrm{rpm}$. In this research we used 800, 1000 and $1200 \mathrm{rpm}$.

$$
N=\frac{30}{\pi} \sqrt{\frac{2 \cdot g \cdot G F}{D_{0}}}=42.3 \sqrt{\frac{G F}{D_{0}}}
$$




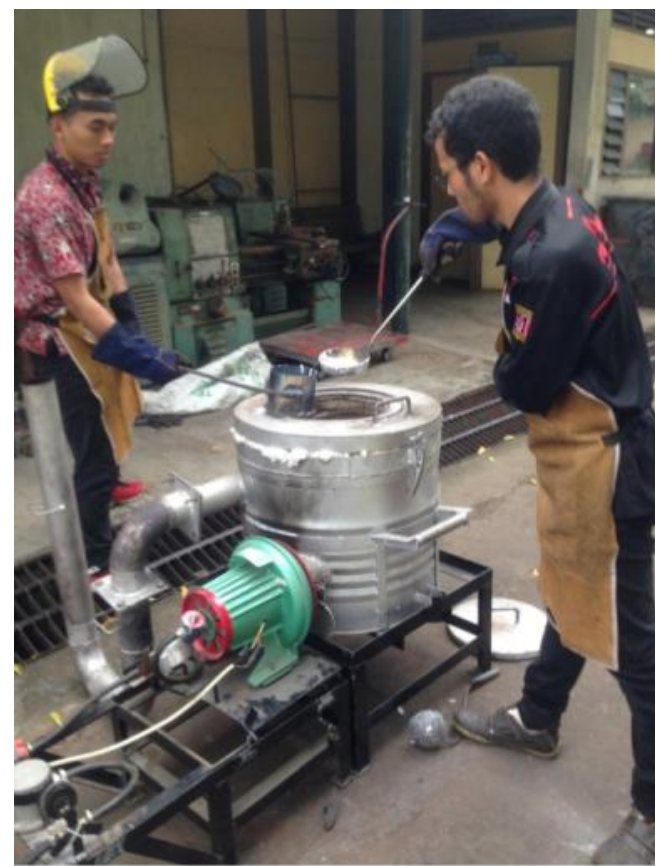

Fig. 4. Aluminum smelting process

Fig. 4, 5 and 6 shows the aluminum smelting process, centrifugal casting process and release process of casting product. All the process was done in fabrication workshop Yogyakarta State University. The chrusible furnace used for smelting process.

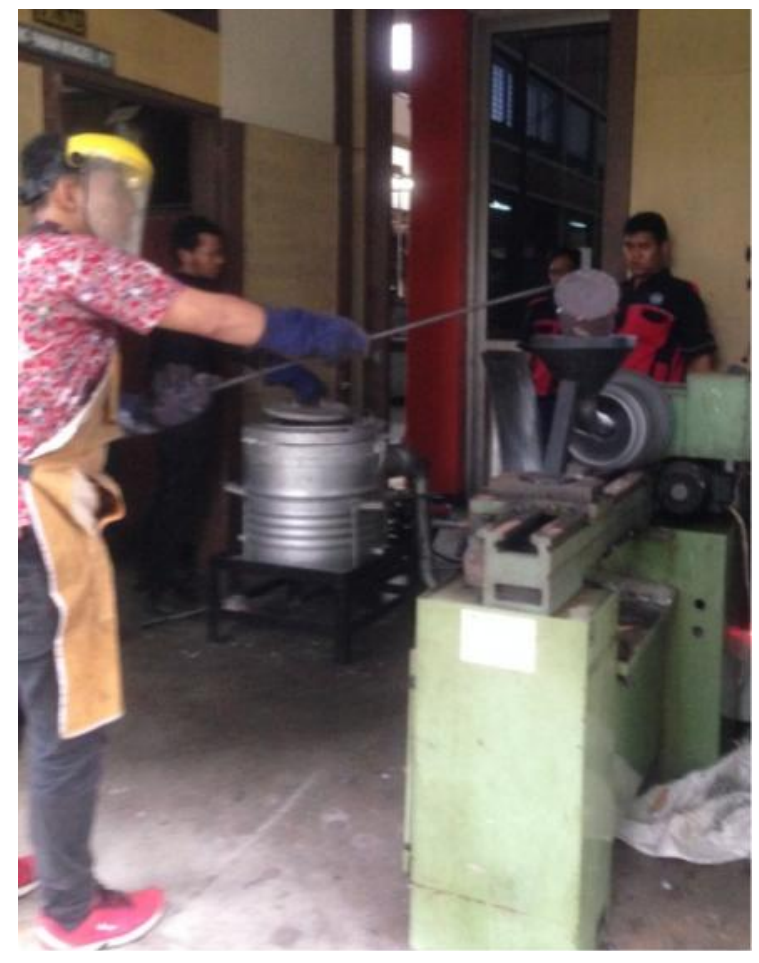

Fig. 5. Centrifugal casting process

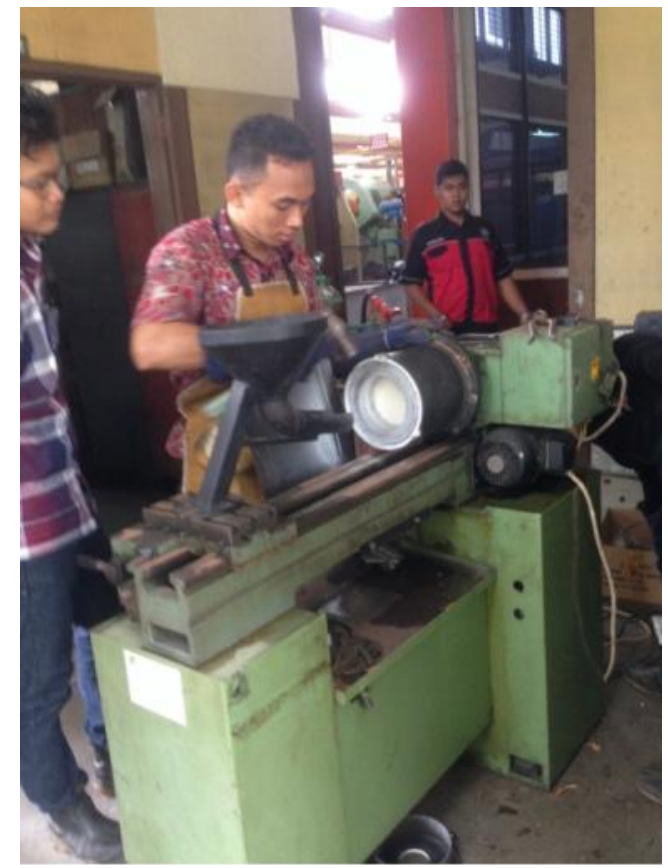

Fig. 6. Release process of casting product

Before casting process we should prepare the centrifugal casting machine. The centrifugal casting need to be cleaned first so that the casting process smoothly. Before our work is started we should prepare the safety work equipment, i.e. work clothes, gloves, protective glass, and work shoes.

\section{RESULT AND DISCUSSION}

Centrifugal force causes the solidification process from the outer surface to the inner. The solidification is better than gravity casting. Jostrad [8], microstructure and good solidification will increasing the mechanics characteristic of material. The negatif side of centrifugal casting is pressure in the molten metal caused high pressure of the mold. The mold should can stand of the molten metal pressure. If the mold can not stand with the pressure, it will broken when pouring process of molten metal. The pressure of molten metal causes the molten metal will flow quikly. This flow is faster than gravity casting. The high velocity causes the erosion level of metal flow increase. This condition requires surface resistance is strong enough to resist erosion due to the flow of metal.

The constriction of molten metal serves as an addition to the flow rate. This is very important to make thin portion object. This portion need the strong mold.

Fig. 7 shows the aluminum casting product. Fig. 7(a) shows the aluminum casting product before turning process and Fig. 7(b) after turning process. The aluminum casting product still need machining process, because the surface still rough and there are many crust in outer side. The data of microstructure and hardness test was taken after turning process. 


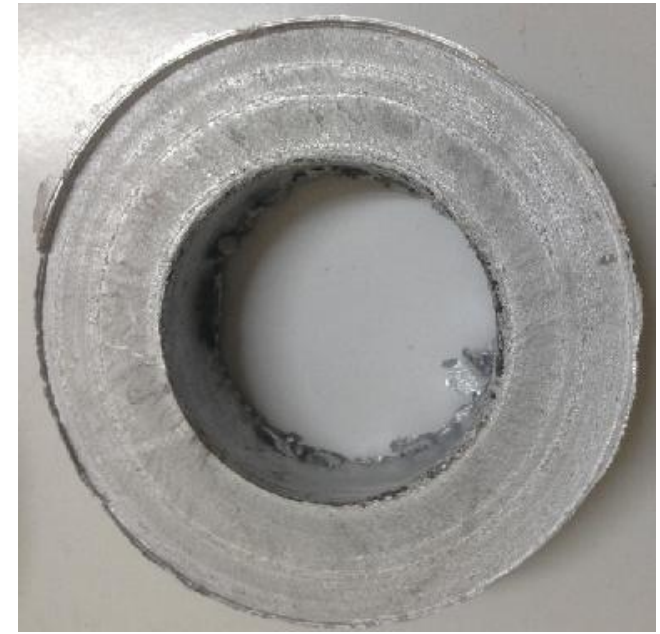

(a) before turning

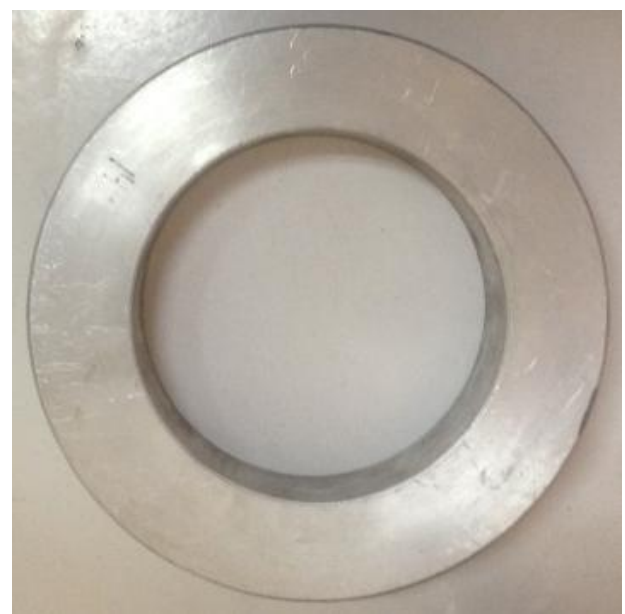

(b) after turning

Fig. 7. Casting product

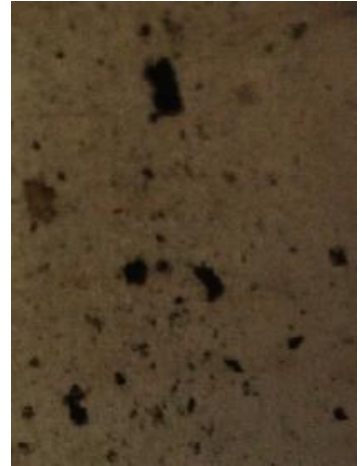

(a)

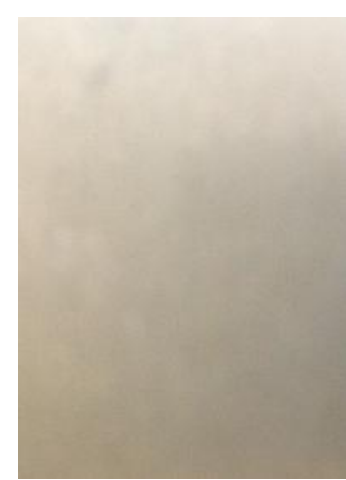

(b)
Fig. 8. Porousity of casting product after turning process (a) inside (b) outside

Fig. 8 shows porous of both sides, which are outer and inner side. From the Fig. seen that the porous occured on the inside of the tube. This condition in line whit the centrifugal force theory that the higher force happen in the outer radius.
The material having large density will accumulate on the outer radius and the material having small density will accumulate in the inner radius. Hopely, we get the large density in the outer diameter.

The data of hardness test and microstructure of specimens taken radially, form outer to inner diameter. Hardness test result in HRC and microstructure in the Fig. of microstructure using 100 times and 400 times in magnification. Each casting product taken specimens on the four sides simetrically, see Fig. 9. Each side taken five points from the outer to inner diameter.

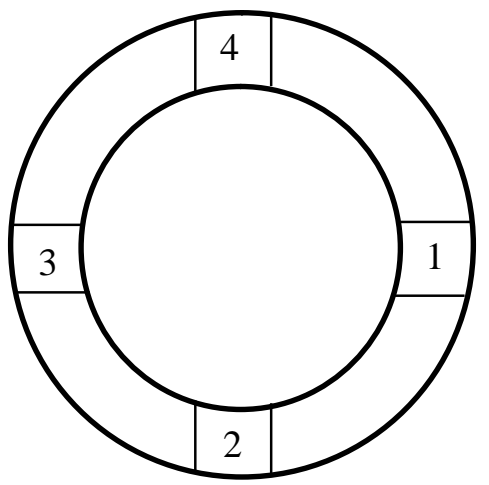

Fig. 9. The side of data retrieval

Fig. 10, 11 and 12 shows the hardness test HRC of casting product using rotational speed in 800, 1000 and $1200 \mathrm{rpm}$, respectively. The data was taken from the outer diameter to the inner. From the Fig. can be concluded that the hardness test result in the outer diameter is more hard than the inner. Maximum hardness test result is $182,87 \mathrm{HRC}$ for rotation speed $1000 \mathrm{rpm}$, getting to the inside diameter the hardness of materials getting soft until the nature of aluminum characteristic. From the outer dimeter until $5 \mathrm{~mm}$ thickness, the hardness characteristic was higher than natural aluminum characteristic. This result in line with the theory, i.e. centrifugal force will increase and compress the aluminum castings.

The rotation speed $1000 \mathrm{rpm}$ was the best result of casting product. This result in line with the theory by calculation result was $970,87 \mathrm{rpm}$.

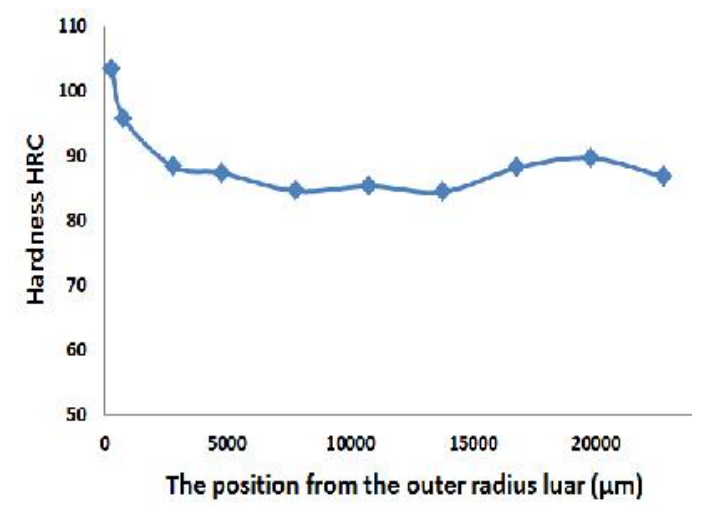

Fig. 10. Hardness test result in $800 \mathrm{rpm}$ 


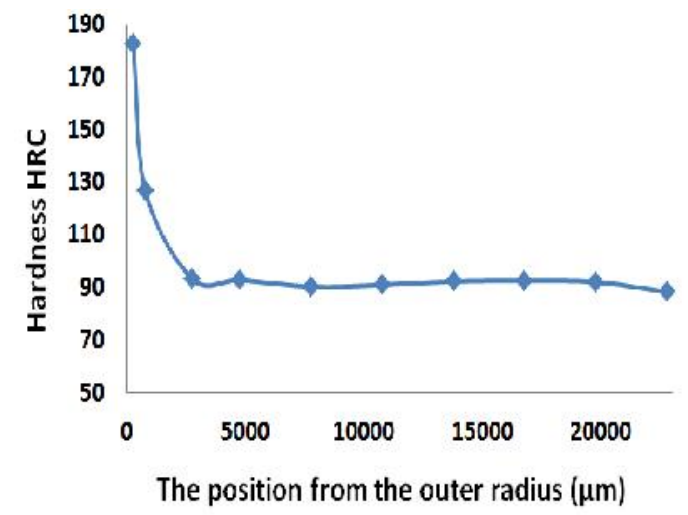

Fig. 11. Hardness test result in $1000 \mathrm{rpm}$

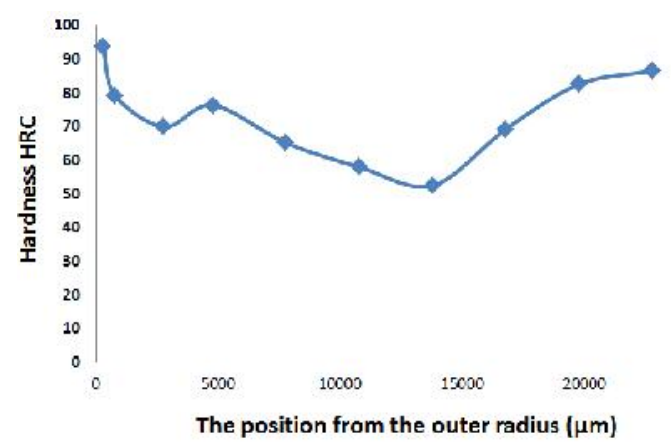

Fig. 12. Hardness test result in $1200 \mathrm{rpm}$

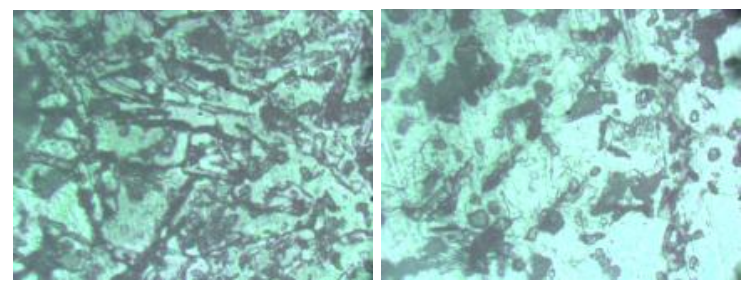

(a) Point 1

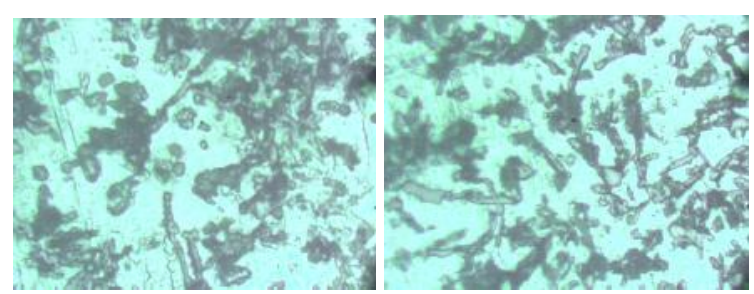

(b) Point 2

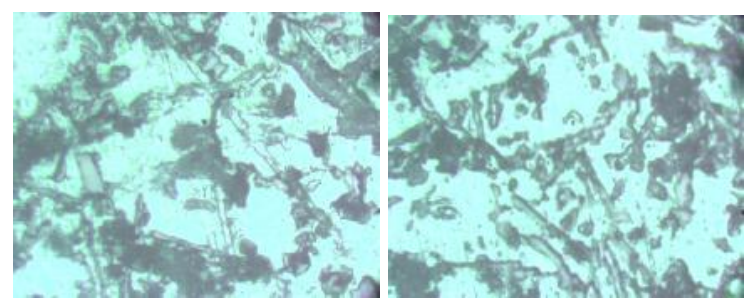

(c) Point 3

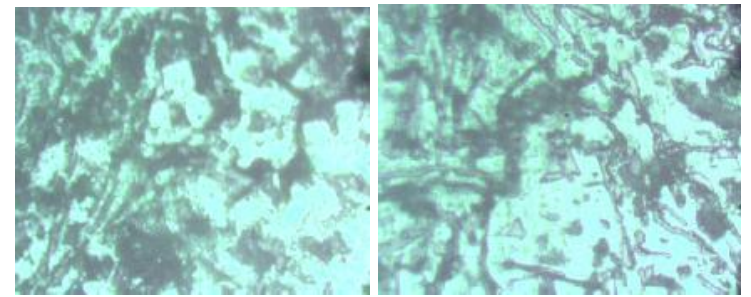

(d) Point 4

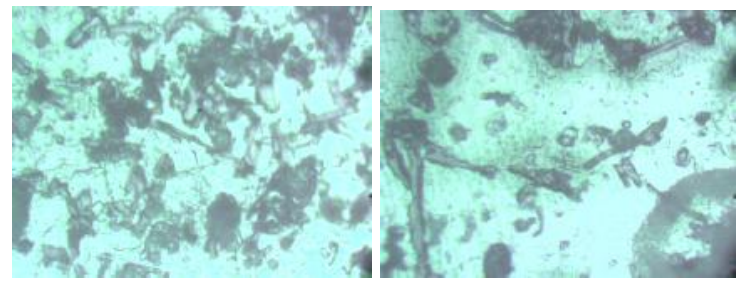

(e) Point 5

Fig. 13. Microstructure of casting product

Fig. 13 shows the microscopic struture of casting product. The camera which magnification $400 \mathrm{x}$ used in present research. Point 1 is the position $300 \mu \mathrm{m}$ from the outer diameter has the tightes grain boundaries. This condition shows the biggest density. The big density shows the high hardness.

The grain boundaries shows increasingly tenous in point 2 , 3 and 4, which has distance $800 \mu \mathrm{m}, 2800 \mu \mathrm{m}$ and $4800 \mu \mathrm{m}$ respectively. However, the grain boundaries in point 5 , which has distance $7800 \mu \mathrm{m}$ and so on tend to be constant. This condition shows that the density tend to be constant start from point 5. This result is in line with the hardness test and the theory in the reference.

\section{CONCLUSION}

1. The porousity occurs in the inner diameter of casting product. In order to obtain the desired casting product it is necessary to estimete the excess so that the porous part can be taken.

2. Material hardness decreases from the outer to inner diameter and tend to be constant in the certain diemeter. The material hardness in certain diameter same with the nature aluminum.

3. The grain boundaries has the tightes on the outer diameter and increasingly tenous to the inner diameter. The grain boundaries tend to be constant in the certain diameter. It's mean the density decreases from the outer to the inner diameter and tend to be constant in the certain diameter.

\section{ACKNOWLEDGEMENT}

The research was supported by the BLU DIPA of Yogyakarta State University funding year 2016. The contract number is 493.d.8/UN34.15/PL/2016 


\section{REFERENCES}

[1] G. Chirita, D. Soares, F. S. Silva, "Advantages of the Centrifugal Casting Technique for the Production of Structural Components with Al-Si Alloys," Material \& Design, 29 pp. 20-27, 2008.

[2] Y. Guojun, Y. Xu, B. Jiang, "The production of highdensity hollow cast-iron bars by vertically continuous casting," Journal of Materials Processing Technology, 212 pp. 15-18, 2012.

[3] Oyewole, and A. M. Sunday, "Design and Fabrication of a Centrifugal Casting Machine," International Journal of Engineering Science and Technology, 3 pp 8204-8210, 2011.

[4] Madhusudhan, S. Narendranath, G.C. Mohan Kumar, "Properties of Centrifugal Casting at Different Rotational of the Die," International Journal of Emerging Technology and Advantage Engineering, 3 pp. 727-731, 2013.
[5] Suryawanshi, S. Kashyap, and A.K. Verma, "Optimize Parameter to Improve the Quality of Centrifugal Casting by Grey Fuzzy Method," International Journal of Computer \& Mathematic Science, 4 pp. 54-59, 2015.

[6] Rajeswari, S.D. Padmaja, K.V. Kalyani, R.C. Krishna, "Improving the Yield of Centrifugal Casting," International Journal of Research in Mechanical Engineering \& Technology. 4 pp. 24-26, 2014.

[7] A.M. Joshi, "Aluminium Foundry Practice," Dept. Of Metallurgical Engg. And Material Science. Indian Institute of Technology Bombay. India, 2007.

[8] L. Jorstad John, M. Rasmussen Wayne, Aluminum Casting Technology. U.S.A: American Foundrymen's Society. Inc., 1993. 